\title{
Predicting WORK PERFORMANCE THROUGH SELECTION INTERVIEW RATINGS AND PSYCHOLOGICAL ASSESSMENT
}

\author{
LIZIWE NZAMA \\ EDCON \\ South Africa \\ MARIÉ DE BEER \\ Department of Industrial and Organisational Psychology \\ University of South Africa \\ South Africa \\ DELÉNE VISSER \\ Department of Industrial and Organisational Psychology \\ University of South Africa \\ South Africa \\ Correspondence to: Marié de Beer \\ e-mail: dbeerm@unisa.ac.za
}

\begin{abstract}
The aim of the study was to establish whether selection interviews used in conjunction with psychological assessments of personality traits and cognitive functioning contribute to predicting work performance. The sample consisted of 102 managers who were appointed recently in a retail structured. structured competency-based interview schedules by interviewing panels, five broad dimensions of and cognitive proces the Five Factor Model as measured by the 15 Factor Questionnaire (15FQ+), and cognitive processing variables (current level of work, potential level of work, and 12 processing competencies) measured by the Cognitive Process Profile (CPP). Work performance was measured through annual performance ratings that focused on measurable outputs of performance objectives. Only two predictor variables correlated statistically significantly with the criterion variable, namely interview ratings ( $r=0.31$ ) and CPP Verbal Abstraction $(r=0.34)$. Following multiple regression, only these variables contributed significantly to predicting work performance, but only $17.8 \%$ of the variance of the criterion was accounted for.
\end{abstract}

Keywords: work performance, psychological assessment, personality traits, cognitive functioning,
Cognitive Process Profile

The recruitment and selection of employees is central to the human resources strategy of most organisations. Organisations use different methods to assess employees in various areas, for example selection, promotion and development (Miner. 1992), Recruitment, or resourcing, as it is currently referred to, regulates the entrance of persons into organisations from outside, whereas promotions regulate the movement of persons within organisations (Visser \& De Jong, 2001). A sound selection process is based on multiple sources of data such as interviews, psychometric tests, references, biodata and performance data (Hoffman \& McPhail, 1998). Most of these methods are regularly adapted or modified as new knowledge about their usage becomes available. The aim of the present study was to assess the effectiveness of specific interview and psychological assessment measures for predicting work performance in a recruitment and selection context.

Interviewing is the second most frequently used method of selecting people for positions; the most common method being the use of biographical data (Schmidt \& Rader, 1999). In recent years there has been a move from unstructured gut-feel interviews to structured interviews that focus on job competencies (McDaniel, Whetzel, Schmidt \& Maurer, 1994). Subsequent studies have supported the higher predictive validity of structured interviews compared to unstructured interviews (Cortina, Goldstein, Payne, Davison \& Gilliland, 2000; McDaniel et al., 1994; Schmidt \& Hunter, 1998; Schmidt \& Rader, 1999). In addition, various types of structured interviews are possible, with the result that the search for the most effective type of interview is ongoing. The predictive validity of interview and psychological assessment results for predicting work performance was explored in the current study.

The period since modern psychological assessment originated more than a hundred years ago has been marked by mixed reactions to the claimed value provided by such assessments, The initial reaction was to accept that psychological assessments added value, but this viewpoint later changed as the reliability validity and fairness of instruments were questioned (Whiston, 2000). As a result of extensive research that has been conducted in the area and consequent improvements that have been made in test development, the status of psychological assessment has been restored in recent years. The recent shift has been towards a better understanding of psychological assessment and therefore a greater acceptance of the value thereof (Whiston, 2000).

In South Africa in particular, the use of psychological assessment as a means of determining the employability of individuals has had a mixed history that was marked in some instances by acceptance and in other instances by scepticism. Two new acts of parliament that were promulgated after the first democratic elections in South Africa in 1994 sparked major changes and development with regard to psychological assessment. The introduction of the Labour Relations Act (1995) (LRA) forced organisations to ensure that their employment practices are fair. Prior to the introduction of the LRA, organisations could select and employ individuals without following any specific method such as interviewing and/or psychometric assessment. Employees were unable to challenge hiring decisions made by 
organisations and this allowed organisations to employ anyone they wished without making the criteria for appointment known. The LRA specifies that organisations must have specific, objective criteria against which individuals are measured when they apply for positions. The use of interviews and psychological tests are ways of measuring individuals against the objective criteria for specific jobs.

The second act of importance in this context was the Employ ment Equity Act (1998) (EEA). When the act was passed, there was much confusion in the $\mathrm{I} / \mathrm{O}$ community regarding the use of psychological tests. The act clearly states that the use of tests is prohibited, unless the user can show that the tests being used are valid, reliable and fair. Many individuals concluded that it would be unfair to use psychological tests in the workplace. The resulting confusion was exacerbated by the lack of familiarity with the code of ethics that governs psychological testing. According to this code of the Health Professions Council of South Africa (HPCSA), organisations may use only tests that comply with the required psychometric properties which include reliability, validity and fair use of tests (HPCSA, 2007).

The introduction of the LRA and EEA contributed to an increased focus on psychological assessment. In South Africa some of the current challenges deal with the discriminatory issues that plagued the country for decades. One of the aims of the legislation is to redress the imbalances that were created by the Apartheid system. The EEA specifically makes provision for individuals who may not have had the opportunity to acquire skills and experience. Companies may not turn down prospective employees solely on the basis of lack of skills and experience. Individuals' abilities to acquire the required skills and experience within a reasonable period of time need to be taken into account and this is generally referred to as potential. The measurement of potential is a relatively new area in psychological assessment and there have been many initiatives to try and provide valid measures of potential, specifically in the cognitive domain.

Organisations need to ensure that their selection processes comply with legal requirements, but also that these processes allow for the selection of individuals who are able to perform specified tasks and contribute effectively to their organisations. However, many organisations do not establish or continue to check the validity of the methods used to make selection decisions (Hoffman \& McPhail, 1998). Using selection processes that have not been validated is not beneficial to organisations, because the value derived from these processes remains unknown. Furthermore, the costs associated with selection strategies that do not work are high, and this relates to both monetary and non-monetary costs (Burnett \& Motowidlo, 1998; Miner, 1992; Schmidt \& Rader, 1999). It is against this background that the present study was undertaken to assess the validity of specific selection methods, namely structured interviews and psychometric tests. The project focused on the value of interviews and psychological assessment (by means of personality and cognitive testing) as used in the areas of resourcing and selection in order to predict job performance.

Varying results have been obtained regarding the use of interviews and assessments in predicting work performance. Interviews are used to assess information about candidates in order to predict future behaviour, but interviews alone are not good predictors of future behaviour (Cornelius, 2001). Research has shown that major differences in results have been obtained, depending on whether structured or unstructured interviews were used. Barrick, Patton and Haugland (2000) report that the more structured the interviews, the more valid the prediction of performance is likely to be. According to them, increased structure in interviews improves the psychometric properties of interviews and hence the improved validity.

Cortina et al. (2000) showed that despite the high predictive validity of cognitive tests, structured interviews account for a significant proportion of the variance when incremental validity was examined, whereas unstructured interviews do not demonstrate any significant incremental validity when considered in conjunction with cognitive tests. Results reported by Schmidt and Rader (1999) that supported the use of structured interviews for predicting job performance yielded a correlation of 0.40 between interview ratings and supervisor ratings. Similarly, in their meta-analysis McDaniel et al. (1994) obtained a correlation of 0.44 between these variables for structured interviews, whereas the correlation was 0.33 for unstructured interviews. Structured interviews furthermore generally have higher face and content validity than unstructured interviews and are less open to bias.

Mount, Witt and Barrick (2000) support the notion that better prediction is achieved when more than one predictor is used, because of incremental validity. For instance, McManus and Kelly (1999) found overlap between biodata and personality, but concluded that the combination of these variables yielded better prediction of performance compared to when they were used individually.

Various researchers have studied the relationship between personality and performance (Sackett, Gruys \& Ellingson, 1998), but in South Africa this topic is still surrounded by controversy (Rothmann \& Coetzer, 2003). Rothmann and Coetzer (2003) found that personality accounted for $28 \%$ of the variance in predicting success at management level. In their study, conscientiousness did not feature as prominently as it did in the Barrick and Mount (1991) study, but the results nevertheless indicated that successful managers generally obtained high conscientiousness scores and were emotionally stable, open to experience and agreeable. The study of Barrick and Mount (1991) was one of the first studies that demonstrated the strong links between personality (in particular, conscientiousness and extraversion) and work performance using the Five Factor Model. Barricket al. (2000) concluded that conscientiousness and extraversion have high predictive validity for job performance across different jobs, but that the remaining factors of the Five Factor Model are relevant for predicting specific jobs.

The Five Factor Model is based on the trait theory of personality and is built on the assumption that some personality traits are universal, consistent and stable over time. It is the most commonly used personality model across different countries, in different contexts and in different interventions (Judge, Higgins, Thoresen \& Barrick, 1999; Mount et al., 2000; Rothmann \& Coetzer, 2003; Schmidt, Kihm \& Robie, 2000). It is also the most integrative model of personality (De Bruin, 2000). Despite support for it, the model has been criticised for being influenced by culture, and for being nomothetic (aimed at inter-individual comparison) instead of idiographic (for intraindividual comparison) in nature (Church, 2001; Schmidt et al., 2000). Furthermore, the Five Factor Model does not account for all of the variance in personality (Paunonen \& Jackson, 2000).

It is clear that ability alone is not the only requirement for being able to do a job well and that personality factors such as motivation are also important. According to McManus and Kelly (1999), personality tests are more predictive of contextual performance than task performance, whereas ability tests tend to be predictive of task performance. These results reflect the multidimensional nature of work performance (Langdon, 2000; Mink, Owen \& Mink, 1993).

Organisations with selection processes that include ability and personality assessments should therefore be in a better position to predict job performance than ones that focus on one aspect only (Sackett et al., 1998). Studies conducted after 1990 generally showed stronger relationships between personality and work performance than ones conducted prior to 1990 (La Grange \& Roodt, 2001). The question arises whether personality can be 
assessed by means of psychometric instruments only. Some of the factors of the Five Factor Model are not readily assessable by means of interviews, but Barrick et al. (2000) maintain that extraversion can be assessed in interviews. Similarly, Cortina et al. (2000) conclude that some aspects of conscientiousness may be accessed via interviews.

One of the measuring instruments that enables one to obtain scores for the Five Factor Model is the Sixteen Personality Factor Questionnaire (16PF) originally developed by Cattell in 1949. It has been criticised when used across cultural groups in South Africa (Abrahams, 2002; Abrahams \& Mauer, 1999), but other researchers claimed that its main shortcomings have been rectified in an adaptation, the 15 Factor Questionnaire (15FQ+), for industrial settings (Prinsloo \& Ebersöhn, 2002). The usefulness of the 16PF and its adaptations has been endorsed by the fact that it is the most frequently used test in a study of 20 South African organisations (Van der Merwe, 2002). The second-order factors of the $15 \mathrm{FQ}+$ were used to measure the factors of the Five Factor Model in the present study.

Like other self-report measures, the $15 \mathrm{FQ}+$ is subject to social desirability responding. Social desirability is a combination of impression management and self-deceptive enhancement (Graziano \& Tobin, 2002). To counter the likelihood of individuals faking their responses when completing personality questionnaires, most questionnaires such as the $15 \mathrm{FQ}+$ have social desirability scales about which respondents are warned at the outset.

In several studies correlations were obtained between social desirability and some of the five-factor dimensions. In particular, Stöber (2001) found that agreeableness correlated with social desirability, whereas emotional stability and conscientiousness correlated with social desirability in other studies (Graziano \& Tobin, 2002; Visser, 2002; Visser \& Du Toit, 2004). Visser (2002) explained these results by indicating that of the five factors, only emotional stability and conscientiousness clearly have positive poles. In the case of the remaining three factors it is under certain circumstances as acceptable to obtain low scores as it is to obtain high scores. There would therefore be no rationale for faking answers to items tapping these three factors unless respondents suspect that particular personality profiles are being sought. Nevertheless, it is likely that the influence of social desirability overall is negligible under certain circumstances. For instance, Mount et al. (2000) report that social desirability had no impact on the predictive validity of the five dimensions, whereas McFarland, Ryan and Ellis (2002) found that faking behaviour decreased when the questionnaire items are randomised, as is the case with the 16PF.

Cognitive tests have been widely used over several decades, but in South Africa the introduction of the LRA resulted in a decline in their use for some years. Nevertheless, previous research has supported the validity of cognitive tests for predicting different criteria such as performance and trainability. Some researchers have found that cognitive tests are the best predictors of various aspects of performance, with mean validities of around 0.45 (Cortina et al., 2000). In the present study, the approach to cognitive testing that was used was cognitive processing adaptive testing, which also includes learning potential (Prinsloo, 2000; Sewell, 1987). Process theories on cognition explain how individuals use their cognitive styles to perform tasks and adjust to the environment (Bergh \& Theron, 1999). The theoretical model used here focuses on five problemsolving processes, namely exploration, analysis, categorisation and integration, logical and lateral reasoning, and retention and recall (Prinsloo, 2000). These processes were assessed by means of the Cognitive Process Profile (CPP), which also provides a measure of learning potential (Prinsloo, 2000).

Two South African tools to measure learning potential that are computerised and use the dynamic assessment model are the
CPP (Prinsloo, 2000) and the Learning Potential Computerised Adaptive Test (LPCAT) (De Beer, 2000). In both instruments the test-train-retest method of assessing potential is used, because individuals are tested to establish their current problemsolving abilities, after which they are given instructions on how to evaluate nonverbal cues and tested again (De Beer, 2000; Prinsloo, 2000). Learning potential on the CPP is reflected on two levels. The first level reflects individuals' learning potential as it refers to the various problem-solving styles and the second level is measured in the context within which the individual is working. The latter is also referred to as levels of work (Jacques, 1998; Prinsloo, 2000). Levels of work are based on Jacques's (1998) stratified systems theory (SST) that identifies seven levels of work and the complexity attached to each level. Stratified systems theory is a holistic theory that incorporates four elements, namely the capability of the individual, series of higher levels of complexity in work, series of higher levels of complexity in organisational structure, and processes like managerial leadership practices (Jacques, 1998). The theory is based on the assumption that it is important to match current and potential individual cognitive functioning to current and potential work environments. Performance is improved when there is a match between individuals' cognitive capabilities and the cognitive demands of the work environment that individuals function in (Jacques, 1998; Prinsloo, 2000). It was decided to employ the CPP in the present study, because it was evident that in South Africa cognitive testing had entered a new era with a strong emphasis on testing for learning potential and the CPP is appropriate for measuring learning potential at managerial level.

The criterion that was predicted in the present study was work performance, Langdon (2000) indicated that contemporary approaches to the definition of performance management currently used in South Africa, as is evident from the literature, differ from traditional definitions that were based on organograms to reflect the way in which work is organised. These traditional approaches are outdated, because they do not always show the relationship between different departments or how work is performed. According to De Lange, Fourie and Van Vuuren (2003), the traditional way of managing performance does not work in most modern organisations as organisations face changes that impact on organisational structures and the way in which work is organised. The way work is conceptualised in an organisation naturally influences how it is measured.

In the current study work performance was defined as a multidimensional construct of how well one performs tasks at work, the initiative taken and how one solves problems - and was measured in terms of a final rating score obtained for each participant. According to this model, work performance is seen as multidimensional and taking place at different levels, such as the business unit, core processes, individual jobs and work groups (Langdon, 2000). Work performance does not only deal with individuals' competence, because other factors can impact on work performance, such as the characteristics of the job, personal circumstances, and the team and organisation individuals work in (Rothmann \& Coetzer, 2003). A multidimensional view of work performance results in greater alignment of work to organisations' overall objectives. This approach also makes the performance review process more meaningful, because discussions between line managers and employees encompass all of the performance dimensions (Langdon, 2000).

It is evident from the foregoing discussion that the criterionrelated validity of the predictors used in this study needed to be examined and that the study might shed light on the benefits of combining certain types of predictors of work performance. The aim of the study was therefore to establish whether selection interviews used in conjunction with psychological assessments (psychometric tests) contribute to predicting work performance. It was hypothesised that selection interview 
ratings, personality traits and cognitive functioning measures would correlate significantly with job performance ratings and that better prediction of job performance can be attained if scores on the three types of predictors are combined.

\section{RESEARCH DESIGN}

\section{Research approach}

A research design that yielded quantitative data that was subsequently analysed statistically was employed. The data consisted of scores on self-report maximal and typical performance psychometric tests as well as panel interview ratings and job performance ratings.

\section{Participants}

The population used in the study was defined as all the persons who were appointed in a retail organisation in managerial positions from middle management to executive levels between January 2002 and September 2003. Before January 2002, psychometric testing had not been introduced at the retail company and therefore no assessment data was available. Another reason for choosing the specific time frame was to ensure that performance ratings would be available for all the participants at the time when the final data-collection process took place in June 2004. Performance reviews at the company were formally conducted at six-monthly intervals only.

The sample consisted of all the persons of the population for whom interview ratings and cognitive assessment data were obtainable. Owing to the lack of an integrated Human Resource (HR) system, some information on specific individuals, particularly interview and performance ratings, was not recorded on the central system. These individuals were omitted from the sample. The final sample consisted of 102 individuals who had interview ratings and cognitive assessment data. One individual for whom personality data was not available was included in the sample and two individuals for whom performance ratings were not available were included.

The mean age of the sample was 36.99 years $(\mathrm{SD}=7.03$ ), and 59 $(57.8 \%)$ were males. In terms of racial composition, there were 25 black participants, 68 white participants, 8 Indian participants and one coloured participant. The majority of the participants were working in the merchandise department $(55.88 \%)$ and $20.59 \%$ were working in the operations department. Only $2.9 \%$ of the sample had not matriculated, whereas $61.7 \%$ of the participants held a tertiary qualification. Females tended to be better educated, because $37.20 \%$ of the females held degrees as against $21.00 \%$ of the males. Similarly, black participants had higher educational qualifications than white participants, because $60 \%$ of them held degrees as against $22 \%$ of the white participants.

\section{Measuring instruments}

The independent variables, namely interview ratings, personality trait assessments, and cognitive functioning were measured by means of structured competency-based interviews, the 15FQ+ (The 15FQ+ Technical Manual, 2002) and the CPP (Prinsloo, 2000). The dependent variable was work performance, which was measured through performance ratings by superiors of the participants.

\section{Competency-based interviews}

Structured competency-based interview schedules that were designed for every managerial position to assess the knowledge and skills or experience attained by the applicants were utilised to obtain a single interview rating for every applicant. For instance, for the position of divisional planning manager, 27 questions were compiled to assess 13 knowledge and skills competencies. Before the interviews took place, the interviewers or interviewing panels had to select certain questions from the schedule to ask, because the applicants were interviewed twice. It was preferable that questions should not be repeated, but the interviewers had to ensure that all the competencies were covered by the questions that they selected. All applicants were asked the same set of questions for specific jobs. The interviews consisted of behavioural questions that were asked about situations in which the applicants had been involved in the past and how the situations had been handled. All the competencies were rated on a five-point scale where a score of 5 indicated an excellent answer that exceeded organisational standards. Finally, a mean interview rating was calculated for every participant.

\section{Factor Ouestionnaire (15FQ+)}

The $15 \mathrm{FQ}+$ is a personality questionnaire designed for occupational use (The 15FQ+ Technical Manual, 2002). The questionnaire is based on the $16 \mathrm{PF}$ and was developed to overcome problems experienced with the use of the 16PF in industrial settings, as documented by Abrahams (2002) and Abrahams and Mauer (1999). The purpose of the $15 \mathrm{FQ}+$ is to measure personality traits that were first defined by Cattell in 1946 (Gregory, 1996), using paper-and-pencil or computerised versions. Areas of personality that are of interest in predicting work performance are included in the 16 traits of personality measured. Measures of the broad dimensions of personality defined by the Five Factor Model may also be obtained when the $15 \mathrm{FQ}+$ is administered. According to the $15 \mathrm{FQ}+$ Technical Manual (2002), Cronbach's alpha reliabilities for a professional sample on the standard form ranged from 0.77 to 0.83 for the 16 traits and 5 broad factors. Similarly, test-retest reliabilities varied from 0.77 to 0.89 (The $15 F Q+$ Technical Manual, 2002). Validity evidence for the $15 \mathrm{FQ}+$ consists of correlations between its scales and the Bar-on EQI and Jung Type Indicator (The $15 \mathrm{FQ}+$ Technical Manual, 2002). Furthermore, when comparing the $15 \mathrm{FQ}+$ with its predecessor (the $15 \mathrm{FQ}$ ), which measured personality factors based on Form $\mathrm{A}$ of the $16 \mathrm{PF}$, substantial correlations between corresponding scales were obtained. The corrected correlations ranged from 0.37 to unity. When the Five Factor Model dimensions were considered, correlations between the 16PF5 and the 15FQ+ broad dimensions ranged from 0.65 for Openness to Experience and 0.88 for Extroversion (The 15FQ+ Technical Manual, 2002).

The 15FQ+ uses a self-report format and consists of 200 items. Respondents have to indicate on a three-point scale how closely the items describe their personal behaviour. The alternatives offered are "agree", "unsure" and "disagree". The participants" responses are captured on a system that generates reports. Apart from interpreting respondents' scores on the various personality traits, the reports also provide derived scores on team roles, leadership roles, subordinate roles, career themes and selling styles. In the present study only the paper-andpencil version of the $15 \mathrm{FQ}+$ was used. The norms developed for South African managerial/professional positions by the test distributor were applied.

The following information from the reports were utilised in the present study:

- Scores on each of the broad dimensions or global factors (factors of the Five Factor Model) measured on a sten scale.

- Social Desirability scores measured on a sten scale were obtained as an indication of the extent to which the questionnaire had been answered honestly. Social desirability scores of 8 or higher were regarded as an indication that the profiles of the individuals concerned needed to be verified, because they may reflect deliberate distortions or unrealistically high self-images (The 15FQ+ Technical Manual, 2002).

Cognitive Process Profile (CPP)

The CPP is a self-administered interactive computer-based cognitive functioning instrument for measuring thinking 
processes and cognitive potential (Prinsloo, 2000). The CPP is based on a combination of the stratified systems theory of Jacques (1998), which identifies seven levels of work with the complexity attached to each of these levels, and cognitive process theory (Prinsloo, 2000). The instrument uses simulation exercises to assess the respondents on approximately 10000 measuring points that are interpreted interactively.

At the outset of every task of the CPP, respondents are given instructions for which they are provided with relevant and irrelevant information to process. Movements of the cursor on the computer monitor are recorded, because these movements reflect how the information is being processed (Prinsloo, 2000).

\section{The CPP assesses the following broad areas:}

- Cognitive processing style as an indication of the approach respondents are likely to take when solving unfamiliar and difficult problems. Fourteen different problem-solving styles are possible. Individuals may display any of these or any combination of styles.

- Suitable work environment which is linked to five different levels of complexity of work depending on the respondents' current and potential levels of cognitive functioning. The seven levels defined by Jacques (1998) had been reduced to five levels in the CPP. They are arranged in order of least to most complex: pure operational, diagnostic accumulation, alternative paths, parallel processing, and pure strategic.

- Strengths and decelopment areas that relate to cognitive functioning that may span across different dimensions

- Learning potential, which is an indication of whether further cognitive improvement is possible.

- Key procissing competencies, which may be linked to the requirements of different jobs.

In addition, respondents are requested to formulate stories based on what they observed on the monitor and to write these

TABLE I

Descriplive slatistics for the independent and dependent variables

\begin{tabular}{|c|c|c|c|c|c|}
\hline VARIABLES & N & M & so & MINIMUM & MAXIMUM \\
\hline Interview ratings & 102 & 3.27 & 0.48 & 1.9 & 4.4 \\
\hline \multicolumn{6}{|l|}{ Personality } \\
\hline Extraversion & 101 & 584 & 1.97 & 1 & 9 \\
\hline Neuroticism & 101 & 533 & 1.76 & 1 & 10 \\
\hline Openness to Experience & 101 & 561 & 1.76 & 1 & 10 \\
\hline Agreeableness & 101 & 4.96 & 157 & 1 & 8 \\
\hline Conscientiousness & 101 & 6.52 & 1.49 & 3 & 10 \\
\hline Social Desirability & 101 & 7.71 & 277 & 1 & 10 \\
\hline \multicolumn{6}{|l|}{ Cognition } \\
\hline Current Level of Work & 102 & 2.28 & 0.78 & 1 & 4 \\
\hline Potential Level of Work & 102 & 2.90 & 0.88 & 1 & 5 \\
\hline Analytical (analytical) & 102 & 48.41 & 21.99 & 6 & 92 \\
\hline Analytical (rule focus) & 102 & 47.17 & 17.82 & 7 & 92 \\
\hline Structuring (categorisation) & 102 & 48.81 & 11.74 & 26 & 88 \\
\hline Structuring (integration) & 102 & 52.88 & 1035 & 25 & 75 \\
\hline Structuring (complexity) & 102 & 5774 & 12.12 & 31 & 84 \\
\hline Logical Reasoning & 102 & 55.90 & 1861 & 5 & 90 \\
\hline Verbal Abstraction & 102 & 5742 & 1526 & 22 & 92 \\
\hline Memory (use of memory) & 102 & 60.76 & 10.40 & 31 & 80 \\
\hline Memory (memory strategies) & 102 & 55.77 & 13.46 & 17 & 80 \\
\hline Judgement & 102 & 46.40 & 13.24 & 3 & 71 \\
\hline Learning (quick insight) & 102 & 60.14 & 10.86 & 34 & 84 \\
\hline Learning (gradual improvement) & 101 & 55.12 & 11.49 & 30 & 80 \\
\hline \multicolumn{6}{|l|}{ Performance ratings } \\
\hline June 2003 & 60 & 110.23 & 4.22 & 100 & 119 \\
\hline September 2003 & 34 & 107.00 & 6.18 & 90 & 116 \\
\hline Overall rating (uune 2004) & 100 & 107.51 & 6.02 & 91 & 117 \\
\hline
\end{tabular}

stories by hand. When testing sessions have been concluded, the administrators have to capture the stories verbatim on the respondents' computer files. The completed protocols have to be submitted to the test developers/distributors where reports are generated against a set of South African norms. Scores are indicated on a scale of 100 points. Reliability and validity evidence is recorded in the manual (Prinsloo, 2000).

In the present study Current Level of Work, Potential Level of Work, and 12 processing competencies that are provided as outcomes of the CPP were included in the data analysis.

\section{Performance ratings}

The performance management system of the company had been introduced in 2000. This system yielded ratings of the job performance of the respondents that were included in the present study to represent the dependent variable.

The aim of the performance management system at the company was to provide the key outputs that are required for each position. Performance reviews that were the evaluation of employees' performance in producing the required outputs took place formally twice a year, during September and again in June. The September review yielded an interim performance rating that indicated whether the agreed objectives for the year would possibly be realised. The June review was considered the annual review that was linked to salary increases, incentives and share allocations. The June 2004 ratings were used as the scores for the overall ratings. In the case of four individuals only, these ratings were not available and therefore their latest available ratings (those of September 2003) were used for the overall ratings.

Every performance objective was rated on a five-point scale and these ratings were weighted to yield an overall performance rating for the employees that could range from 80 to 120 where a high score indicated superior performance. The system was designed so that most of the outputs were measurable, which enhanced the reliability of the procedure. Examples of measurable outputs include sales figures and stock loss percentages,

\section{Procedure}

The data for the study was obtained from the psychologist who was responsible for giving feedback to line managers on the appointments at managerial level, from available assessment reports and from a report from the HR information manager that indicated performance ratings and positions held by the employees. Biographical information was recorded in addition to scores on the independent and dependent variables.

The selection interviews were conducted face-to-face by a panel consisting of potential hiring managers and the HR manager. Members of the panels first awarded scores individually, but the scores were then discussed by the panel members in order to reach a consensus score. The psychometric assessment data and the performance ratings were routinely available and were obtained from records that were available for all the respondents.

\section{RESULTS}

The first step of the analyses involved computing descriptive statistics for the sample on the independent and dependent variables. The results are presented in Table 1.

The mean of the interview ratings was equal to 3.27 , which was slightly above the midpoint of the five-point scale. The mean sten values obtained for the $15 F Q+$ varied between 4.96 and 6.52, which may be regarded as average values when compared with the norm group. The only exception appeared 
to be the sten of 7.71 obtained for Social Desirability, but the large standard deviation of 2.77 meant that this sten was also within one standard deviation from the midpoint on the sten scale. Individuals who obtained Social Desirability scores of more than 8 may have given socially desirable answers when they completed the questionnaire. When the frequencies of the ten possible scores on Social Desirability were examined, it emerged that $45.54 \%$ of the sample scored stens of 10 and that altogether $61.38 \%$ of the sample had scores of 8 or higher. This may have had an effect on the reliability of the personality scores of this group. However, it was not possible to investigate this further using the available data.

With one exception, all the mean scores for the cognitive assessments may be regarded as average when judged against the norm group referred to in the CPP manual (Prinsloo, 2000). The exception was Memory (use of memory), for which the respondents obtained an average score of more than one standard deviation above the mean. The mean overall work performance rating was $107.51(\mathrm{SD}=6.02)$.

As the participants were all appointed in managerial positions, they were categorised into eight primary team roles and five primary leadership styles according to their responses to the $15 \mathrm{FQ}+$ questionnaire. Altogether $67.64 \%$ of the respondents were categorised as Inspector Completer, Implementer or Resource Investigator. This means that the predominant roles likely to be fulfilled by these individuals included following through on tasks, focusing on schedules and targets, and paying attention to detail. Problems are likely to be approached systematically, with ideas being converted into practical plans. This would be achieved by identifying new opportunities and establishing networks with key people or organisations. Only a small portion of the group turned out to be Innovators, Shaper Drivers and Evaluator Critics. The problem-solving approach of this minority group would typically involve focusing on tasks

TABLE I

Descriptive statistics for the independent and dependent variables

\begin{tabular}{|c|c|c|c|c|c|c|c|c|c|c|c|}
\hline & 1 & 2 & 3 & 4 & 5 & 6 & 7 & 8 & 9 & 10 & 11 \\
\hline 1. Interview Ratings & - & & & & & & & & & & \\
\hline 2. Extraversion & 0.08 & $=$ & & & & & & & & & \\
\hline 3. Neuroticism & $-0.21^{*}$ & $-0.32^{* *}$ & - & & & & & & & & \\
\hline 4. Openness to Experience & -0.07 & $0.22^{*}$ & 0.16 & $\bullet$ & & & & & & & \\
\hline 5. Agreeableness & -0.05 & $-0.23^{*}$ & -0.04 & -0.08 & - & & & & & & \\
\hline 6. Conscientiousness & 0.05 & 0.06 & $-0.24^{*}$ & -0.07 & 0.08 & - & & & & & \\
\hline 7. Social Desirability & 0.08 & 0.02 & $-0.29^{* *}$ & -0.05 & $0.29^{* *}$ & -0.04 & - & & & & \\
\hline 8. Current Level of Work & $0.20^{*}$ & $0.26^{* *}$ & -0.08 & 0.13 & -0.02 & $-0.23^{*}$ & -0.09 & - & & & \\
\hline 9. Potential Level of Work & 0.15 & 0.19 & -0.08 & 0.15 & -0.06 & $.0 .20^{*}$ & -0.14 & $0.81^{* *}$ & - & & \\
\hline 10. Analytical (analytical) & 0.02 & 0.10 & 0.08 & 0.06 & 0.02 & -0.18 & -0.17 & $0.78^{\star *}$ & $0.77^{\star *}$ & - & \\
\hline 11. Analytical (rule focus) & 0.01 & 0.01 & 0.15 & 0.14 & -0.01 & $-0.29^{* *}$ & $-0.20^{*}$ & $0.73^{\star *}$ & $0.64^{\star \star}$ & $0.80^{\star *}$ & - \\
\hline 12. Structuring (categorisation) & 0.05 & -0.03 & 0.09 & 0.16 & -0.09 & $-0.24^{*}$ & $-0.25^{\star}$ & $0.63^{* *}$ & $0.59^{\star \star}$ & $0.58^{\star *}$ & $0.82^{\star *}$ \\
\hline 13. Structuring (integration) & 0.09 & 0.16 & -0.01 & 0.15 & -0.06 & $-0.21^{*}$ & -0.09 & $0.89 * *$ & $0.86^{\star \star}$ & $0.79^{\star \star}$ & $0.75^{\star \star}$ \\
\hline 14. Structuring (complexity) & 0.13 & $0.22^{*}$ & -0.02 & 0.19 & 0.00 & $-0.21^{*}$ & 0.04 & $0.84 * *$ & $0.85^{\star *}$ & $0.76^{* *}$ & $0.62^{* *}$ \\
\hline 15. Logical Reasoning & 0.16 & $0.23^{*}$ & -0.05 & 0.16 & -0.02 & $-0.22^{*}$ & -0.07 & $0.82^{\star \star}$ & $0.86^{\star \star}$ & $0.79^{* *}$ & $0.63^{\star *}$ \\
\hline 16. Verbal Abstraction & 0.12 & 0.09 & -0.09 & 0.10 & 0.00 & -0.19 & 0.01 & $0.57^{\star \star}$ & $0.69^{\star \star}$ & $043^{\star *}$ & $030^{* *}$ \\
\hline 17. Memory (use of memory) & 0.11 & 016 & -0.03 & 0.17 & -0.13 & -0.13 & -0.09 & $0.76^{\star \star}$ & $0.74^{\star *}$ & $0.62^{\star *}$ & $0.64^{* \star}$ \\
\hline 18. Memory (memory strategies) & 0.15 & 0.05 & 0.02 & 006 & $-0,11$ & -0.11 & -0.18 & $0.69^{* *}$ & $0.61^{* *}$ & $0.52^{\star \star}$ & $0.71^{\star *}$ \\
\hline 19. Judgement & 0.06 & 0.18 & 0.01 & 0.13 & -0.03 & -0.14 & -0.14 & $0.83^{\star \hbar}$ & $0.84^{\star \star}$ & $0.87^{\star *}$ & $0.75^{\star *}$ \\
\hline 20. Learning (quick insight) & 0.11 & 0.14 & 0.00 & 0.13 & -0.08 & -0.13 & -0.14 & $0.86^{\star \star n}$ & $085^{\star \star}$ & $0.80^{* *}$ & $0.74^{* *}$ \\
\hline 21. Learning (gradual improvement) & 0.01 & 0.05 & 0.05 & 0.03 & -0.15 & -0.01 & -0.19 & $0.55^{\star \star}$ & $0.53^{\star *}$ & $0.60^{\star *}$ & $059^{* *}$ \\
\hline \multirow[t]{2}{*}{ 22. Performance rating } & $0.31^{* *}$ & -0.05 & -0.01 & -0.13 & -0.16 & -0.15 & -0.10 & 0.17 & 0.15 & 0.09 & 0.03 \\
\hline & 12 & 13 & 14 & 15 & 16 & 17 & 18 & 19 & 20 & 21 & 22 \\
\hline
\end{tabular}

1. Interview Ratings

2. Extraversion

3. Neuroticism

4. Openness to Experience

5. Agreeableness

6. Conscientiousness

7 Social Desirability

8. Current Level of Work

9. Potential Level of Work

10. Analytical (analytical)

11. Analytical (rule focus)

12. Structuring (categorisation)

13. Structuring (integration)

14. Structuring (complexity)

15. Logical Reasoning

16. Verbal Abstraction

17. Memory (use of memory)

18. Memory (memory stralegies)

19. Judgement

20. Learning (quick insight)

21 Learning (gradual improvement) $0.59^{*}$

22. Performance rating

0.7
0.5
0.5
0.3
0.6
0.8
0.65
0.7
0.5
0.08

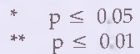


by providing direction and energy to the group, creativity, strategic thinking as well as objectivity and sound judgement. Although there was no representation of Coordinators as a primary team role, it came up as the highest secondary team role. These results were not in line with expectations for this group of middle to senior managers, whose role it was to shape and drive the business in order to achieve results, while taking people issues into account. The dominant primary team roles in this sample indicated a strong operational or implementationfocused approach, whereas the focus should have been on tactical and strategic team roles such as the roles of Coordinator, Shaper Driver and Innovator.

With regard to the primary leadcrship styles, $31.37 \%$ of the sample followed the Directive style and $25.49 \%$ followed the Negotiative style. Representation for the Delegative, Participative and Consultative styles ranged from $6.86 \%$ to $17.65 \%$. This implies that decisions tended to be made by leaders with whom the final decisions of which ideas to adopt tended to lie. Only $6.86 \%$ of the sample preferred the Delegative style, which probably means that not enough freedom was given to employees when tasks and projects were assigned to them. Combined with the weak representation of the Participative and Consultative styles, it is evident that this group of managers might tend to disregard the potential that their subordinates display.

The reader is cautioned about the categorisation of participants into team roles and leadership styles by the $15 \mathrm{FQ}+$. The nature of the categorisation dictates that participants are assigned to only one or two of the roles and styles, although they may also show strong preferences for other styles that are not included in the interpretation due to the nature of the scoring. Scores for every participant on each of the styles might possibly have yielded a very different protile of the sample.

The next step of the analyses entailed computing the intercorrelations between the independent and dependent variables. The results are reported in Table 2.

The most striking feature of the intercorrelation matrix is that only two predictor variables correlated statistically significantly with the criterion variable Work Performance rating, namely Interview Ratings ( $r=0.31, p=0.002)$ and Verbal Abstraction $(r=0.34, p=0.001)$. Both of these correlations represent medium effect sizes.

TABLE 3

Stepwise multiple regession of Performance ratings on the independent variables

\begin{tabular}{lrrccc}
\hline & $\begin{array}{c}\text { SUM OF } \\
\text { SQUARES }\end{array}$ & df & MEAN SQUARE & F & P \\
\hline $\begin{array}{l}\text { Verbal Abstraction } \\
\text { Regression }\end{array}$ & 370.89 & 1 & 370.89 & 11.26 & $0.001^{* *}$ \\
Residual & 3163.60 & 96 & 32.95 & & \\
Total & 3534.48 & 97 & & & \\
Interview rating: & 630.70 & 2 & 315.35 & 10.32 & $0.000^{* *}$ \\
Regression & 2903.78 & 95 & 30566 & & \\
Residual & 3534.48 & 97 & & & \\
Total & & & & & \\
\hline
\end{tabular}

$* \mathrm{~F} \leq 005 * * \mathrm{~F} \leq 001$

\begin{tabular}{|c|c|c|c|c|c|}
\hline \multirow[t]{2}{*}{ MODEL } & \multicolumn{2}{|c|}{$\begin{array}{l}\text { UNSTANDARDISED } \\
\text { COEFFICIENTS }\end{array}$} & \multirow{2}{*}{$\begin{array}{l}\text { STANDARDISED } \\
\text { COEFFICIENTS } \\
\text { Beta }\end{array}$} & \multirow[t]{2}{*}{$t$} & \multirow[t]{2}{*}{ P } \\
\hline & B & SE & & & \\
\hline 1) Constant & 99.76 & 2,40 & & 41,64 & $0.000^{*+}$ \\
\hline Verbal Abstraction & 0.13 & 0.04 & 0.32 & 3.36 & $0.001^{* *}$ \\
\hline 2) Constant & 89,41 & 4.23 & & 21,12 & $0.000^{* *}$ \\
\hline Verbal Abstraction & 0.12 & 0.39 & 0.30 & 3.17 & $0.002^{* *}$ \\
\hline Interview ratings & 3,36 & 1.15 & 0.27 & 2.92 & $0.004^{* *}$ \\
\hline
\end{tabular}

Interview ratings

$3.36 \quad 1.15$

0.27

$2920004^{* *}$
Another striking feature of the intercorrelation matrix is the strong correlations between the cognitive measures of the CPP, which indicate that these measures are not independent, but that they represent a single underlying cognitive factor. The use of 14 different cognitive measures therefore cannot be justified, because a more parsimonious description of cognitive functioning is called for. The correlation between Current and Potential Levels of Work was equal to 0.81 ( $p \leq 0.001$ ) and these two variables also correlated strongly with all of the cognitive processing competencies. The correlations ranged from 0.53 to 0.89 representing large effect sizes. The intercorrelations between the cognitive processing competencies represented medium to large effect sizes and ranged from 0.31 to 0.90 . Altogether $94 \%$ of these correlations represented large effect sizes $(\geq 0.50)$.

A different picture emerged with regard to the intercorrelations among the five broad dimensions of personality, because the variables were generally not strongly correlated. Extraversion correlated significantly with Neuroticism $(r=-0.32, p=0.001)$, Openness to Experience $(r=0.22, p=0.027)$ and Agreeableness $(r=-0.23, p=0.020)$. Furthermore, Neuroticism correlated negatively with Conscientiousness $(r=-0.24, p=0 .(014)$. The remainder of the intercorrelations between the Five Factor dimensions were not statistically significant. Social Desirability correlated significantly with Neuroticism $(r=-0.29, p=0.003)$ and Agreeableness $(r=0.29, p=0.003)$.

It should be noted that none of the cognitive variables correlated significantly with Interview Ratings, but Interview Ratings correlated significantly with Neuroticism $(r=-0.21, p=0.032)$. No strong correlations that yielded at least medium effect sizes were obtained between the personality variables and the cognitive functioning variables. However, in terms of statistical significance, two variables reached statistical significance at the 0.01 level, namely the correlations between Extraversion and Current Level of Work $(r=0.26, p=0.009)$ and between Conscientiousness and Analytical (rule focus) where $r$ was equal to $-0.29(p=0.003)$.

The final step in the analysis of the data was to conduct a stepwise multiple regression analysis to predict Performance Ratings. All of the independent variables were entered into the regression model and the obtained results were as expected from the intercorrelations between the variables, namely that only Interview Ratings and Verbal Abstraction contributed significantly to the prediction of Performance Ratings. The results of the regression analysis are presented in Table 3.

Verbal Abstraction yielded a squared multiple correlation coefficient of 0.105 (Adjusted $R^{2}=0.096$ ). When Interview Ratings was added to the regression, $\mathrm{R}$ was equal to 0.42 and $R$ squared increased to 0.178 (Adjusted $R^{2}=0.161$ ). Considering the number and nature of the variables entered, the regression results were disappointing, because only $17.8 \%$ of the variance of the Performance Ratings was accounted for by the independent variables.

\section{DISCUSSION}

The main aim of the study was to establish whether competencybased selection interviews used in conjunction with tests of cognitive processing and learning potential and measures of the Five Factor model contributed significantly to predicting work performance. The result that only two out of twenty-two possible predictors correlated significantly with the criterion Work Performance was both unexpected and disappointing. None of the variables of the Five Factor model of personality correlated statistically significantly with Work Performance. Only Interview Ratings and one of the cognitive processing styles of the CPP (Verbal Abstraction) yielded medium effect size correlations with the criterion 
The correlations of interview ratings with the other variables demonstrated the value of using structured competency-based interviews for predicting work performance. Interview Ratings correlated substantially with the criterion, thereby supporting the findings of other researchers (McDaniel et al., 1994; Pearlman, Schmidt \& Hamner, 1983; Salgado \& Moscoso, 2002; Schmidt \& Rader, 1999). Furthermore, most of the correlations of Interview Ratings with the other predictors failed to reach statistical significance or at best represented small effect sizes. In particular, Interview Ratings did not correlate with any of the cognitive variables, except for a small effect size correlation between Interview Ratings and Current Level of Work. These results are contrary to those obtained by Cortina et al. (2000), who reported a correlation of 0.27 between structured interviews and cognitive ability, but our findings imply that interview ratings made a unique contribution to predicting the criterion.

According to the results for this sample and approach, the five factors of the $15 \mathrm{FQ}+$ could not be regarded as predictors of work performance. These findings are similar to results reported by Sackett et al. (1998), but are not in support of those found in several other studies (Barrick et al, 2000; Barrick \& Mount, 1991; Cortina et al., 2000; La Grange \& Roodt, 2001; Tett, Jackson, Rothstein, \& Reddon, 1994) that supported the predictive validity of personality factors. The obtained results cannot be ascribed to the use of clinical personality tests as similar results have been explained (Gatewood \& Field, 1994), because the personality test used here, the $15 \mathrm{FQ}+$, was developed for use in the workplace.

A positive feat ure of the correlations was that the five dimensions of personality were generally not strongly intercorrelated, implying that the five factors constituted relatively independent measures. The results of the Social Desirability scale corroborated the findings of some previous research, because Social Desirability correlated statistically significantly with Agreeableness (Graziano \& Tobin, 2002; Stöber, 2001) and Neuroticism (Graziano \& Tobin, 2002; Visser, 2002; Visser \& Du Toit, 2004). The correlation between Agreeableness and Social Desirability may possibly be linked to the impression management component of social desirability. It is possible that the respondents' scores on the personality dimensions were contaminated by socially desirable responding, because their mean score of 7.71 on the Social Desirability scale is an indication that the profiles of some of them are not valid (Graziano \& Tobin, 2002; McFarland et al,, 2002). This is a source of concern, because it implies that a portion of the hiring decisions made on the basis of these personality measures may have been incorrect.

The strong intercorrelations between the cognitive variables point to a large degree of redundancy in measurement due to overlapping (common) variances. This problem may have been addressed by reducing the number of variables by means of factor analysis, but it remains doubtful whether any improvement in predictive validity will result from such a step. This could be investigated through further research using larger samples. Certainly in this study the results for the cognitive measurements did not support the use of cognitive functioning as measured by the CPP as a predictor of work performance. For instance, Work Performance did not correlate with Current or Potential Levels of Work. Verbal Abstraction was the only cognitive processing competency that showed a significant correlation with Performance Ratings. These findings are in direct contrast to previous research that has indicated that cognition may be regarded as the single best predictor of different aspects of performance as has generally been found in studies that included various meta-analyses (Cortina et al., 2000; Schmidt \& Hunter, 1998; Vinchur, Schippmann, Switzer, \& Roth, 1998).
A stepwise multiple regression confirmed the correlation results, because only two variables, Verbal Abstraction (CPP) and Interview Ratings, contributed significantly to the prediction of work performance. None of the personality variables added any value to the prediction. Considering the weak multiple regression coefficient obtained, the results of the present study was not encouraging. Apart from the contribution of the interview ratings, the personality and cognitive variables generally did not provide evidence for their predictive validity.

A further cause for concern regarding the use of the CPP in the company involved in the study was noted. It was found that the average current level of work of the respondents was Level 2: Diagnostic Accumulation, which is linked to supervisory and specialist jobs in the organisation. The average potential level of work for the respondents was Level 3: Alternative Pathways, which is linked to middle and senior managerial responsibilities. Given that all the respondents were already in middle or senior management positions and had obtained satisfactory performance ratings, one would expect that they would currently be operating at Level 3 and not at Level 2 . Furthermore, one would expect that their average potential level of work would have been Level 4: Parallel Processing, or Level 5: Pure Strategic. Clearly, the levels of cognitive complexity as measured by the CPP and as contextualised in the organisation do not match the conception of successful performance in the organisation at the managerial level,

Overall the present study highlighted the unique contribution that structured interviews make to the prediction of performance. This finding confirmed the conclusions of McDaniel et al. (1994), Pearlman et al. (1983) and Schmidt and Rader (1999) regarding the importance of structured interviews in the selection process, because these researchers also obtained substantial correlations between structured interview ratings and job performance.

The disappointing results regarding the personality and cognitive variables may to some extent have been due to some shortcomings of the study and it is recommended that the study be repeated in a design that corrects possible shortcomings. Obvious shortcomings of the study were that the sample size was somewhat small for conducting multiple regression analyses and that restriction of range was present due to the homogeneous sample, because it consisted of individuals who were appointed into managerial positions. The relatively small standard deviation of the work performance scores is indeed an indication that restriction of range possibly influenced the magnitude of the correlations. A further possible confounding factor is that the respondents were employed in several departments of the retail organisation, although the majority were attached to the merchandise department. It may be that the measures of work performance were not directly comparable across the various departments. Nevertheless, great care was taken to focus on measurable outputs.

\section{REFERENCES}

Abrahams, A. \& Mauer, K.F. (1999). The comparability of the constructs of the $16 \mathrm{PF}$ in the South African context. South African Journal of Psychology, 25(1), 53-59.

Abrahams, F. (2002). The (un)fair usage of the 16 PF (SA 92) in South Africa: a response to $\mathrm{CH}$ Prinsloo and I Ebersöhn. South African Journal of Psychology, 32(3), 58-61.

Barrick, M.R. \& Mount. M.K. (1991). The big five personality dimensions of job performance: a meta analysis. Personnel Psychology, 44, 1-26.

Barrick, M.R, Patton, G.K. \& Haugland, S.N. (2000). Accuracy of interviewer judgments of job applicant personality traits. Personnel Psychology, 53, 925-951.

Bergh, Z.C. \& Theron, A.L. (1999). Psychology in the work context. Cape Town: Oxford University Press. 
Burnett, J.R. \& Motowidlo, S.J. (1998). Relations between different sources of information in the structured selection interview. Personnel Psychology, 51, 963-983.

Church, A.T. (2001). Personality measurement in cross cultural perspective. Journal of Personality, 69(6), 979-1005.

Cornelius, N. (2001). Human Resource's Management: a managerial perspective, London: Thomson.

Cortina, J.M., Goldstein, N.B., Payne, S.C., Davison, H.K. \& Gilliland, S.W. (2000). The incremental validity of interview scoresover and abovecognitiveability and conscientiousness scores. Personnel Psychology, 53, 325-351.

De Beer, M. (2000). The construction and evaluation of a dynamic computerized adaptive test for the measurement of learning potentinl. Unpublished Doctoral Dissertation. Pretoria: University of South Africa.

De Bruin, G.P. (2000). An inter battery factor analysis of the Comrey personality scales and the $16 \mathrm{PF}$ questionnaire. Jouminl of Industrial Psychology, 26(3), 4-7.

De Lange, M., Fourie, L. \& Van Vuuren, L.J. (2003). Reliability of competency based, multi-dimensional, multi-rater performance ratings. A Journal of Industrial Psychology, 29(2), $39-48$.

Employment Equity Act, No 55 (1998). Government Gazette, 400 (19370). Cape Town, 19 October 1998.

Gatewood, R.D. \& Field, H.S. (1994). Human Resources Selection Fort Worth, TX: Dryden

Graziano, WG \& Tobin, R.M. (2002). Agreeableness: dimension of personality or social desirability artifact? fournal of Personality, 70(5), 695-727.

Gregory, R.J. (1996). Psychological testing, history, principles and applications (2nd Ed). Boston: Allyn \& Bacon.

Hoffman, C.C. \& McPhail, S.M. (1998). Exploring options for supporting test use in situations precluding local validation. Persommel Psychology, 51(3-4), 987-1003.

HPCSA. (2007). Ethical and professional rules of the Health Professions Council of South Africa as promulgated in Government Gazetter R717/2006 (2nd Ed.). Pretoria: HPCSA.

Jacques, E. (1998). Rerquisite organization, Arlington, VA: Cason Hall.

Judge, T.A., Higgins, C.A., Thoresen, C.J. \& Barrick, M.R. (1999) The big five personality traits, general mental ability, and career success across the life span. Personnel Psychology, 52, 621-652.

Labour Relations Act, No 66 (1995). Government Gazette, No 1877. Cape Town, 13 December 1995

La Grange, L. \& Roodt. G. (2001). Personality and cognitive ability as predictors of the job performance of insurance sales people. Journal of Industrial Psychology, 27(3), 35-43.

Langdon, DG. (2000). Aligning performance: improving people systems and orginizations. San Francisco: Jossey-Bass Pfeiffer.

McDaniel, M.A., Whetzel, D.L., Schmidt, EL. \& Maurer, S.D. (1994). The validity of employment interviews: a comprehensive review and meta-analysis. Journal of Applied Psychology, 79(4), 599-16.

McFarland, L.A., Ryan, A. \& Ellis. A. (2002). Item placement on a personality measure: effects of faking behaviour and test measurement properties. Toumal of Personality Assessment, $78(2), 348-369$

McManus, M.A. \& Kelly, M.L. (1999). Personality measures and biodata: evidence regarding their incremental predictive validity in the life insurance industry. Persomnel Psychology, $52(1 / 2), 137-148$

Miner, J.B. (1992). Industrial Organizational Psychology. New York: McGraw-Hill.

Mink, O.G., Owen, K.Q. \& Mink. B.P. (1993). Deweloping high performance people: the art of conching. New York: AddisonWesley.
Mount, M.K., Witt, L.A. \& Barrick, M.R. (2000). Incremental validity of empirically keyed biodata scales over GMA and Five Factor personality constructs. Personnel Psychology, $53(1-2), 299-323$

Paunonen, S.V. \& Jackson, D.N. (2000). What is beyond the Big 5? Plenty. Journal of Personality, 68(5), 821-835.

Pearlman, K., Schmidt, K.L.\& Hamner, W.C. (1983). Contemporary problems in personnel (3rd Ed.). New York: John Wiley.

Prinsloo, C. H. \& Ebersöhn, I. (2002). Fair usage of the 16 PF in personality assessment in SA: a response to Abraham \& Mauer with special reference to issues of research methodology. South Africuin Journal of Psychology, 32(3), 4857.

Prinsloo, M. (2000). Cognitive process profile: Training manual. CPP training manual for workshop presented to Edcon, Johannesburg.

Rothmann, S. \& Coetzer. E.P. (2003). The big 5 personality dimensions and job performance. Journal of Industrial Psychology, 29(1), 68-74

Sackett, P.R, Gruys, M.L. \& Ellingson, J.E. (1998). Abilitypersonality interactions when predicting job performance. Journal of Applied Psychology, 83(4), 545-556.

Salgado, J.F. \& Moscoso, S. (2002). Comprehensive meta-analysis of the construct validity of the employment interview. European Journal of Work and Organizational Psychology, 11(3), 299-324.

Schmidt, F.L., \& Hunter, J.E. (1998). The validity and utility of selection methods in personnel psychology: practical and theoretical implications of 85 years of research findings. Psychological Bulletin, 124(2), 262-274.

Schmidt, F.L. \& Rader, M. (1999). Exploring the boundary conditions for interview validity: meta-analytic validity findings for a new interview type. Persomel Psychology, 52, 445-464.

Schmidt, M.J., Kihm, J. A. \& Robie, C. (2000). Development of a global measure of personality. Personnel Psycloology, 53, 153-193.

Sewell, T.E. (1987). Dynamic assessment as a nondiscriminatory procedure In C.S. Lidz (Ed). Dymamic Assessment: an integrated approach to evaluating learning potential. New York: Guilford, pp. 426-442.

Stöber, J. (2001). The Social Desirability Scale 17 (SDS-17) convergent validity, discriminant validity \& relationship with age. European Journal of Psychological Assessment, 17(3), 222-232.

Tett, R.P., Jackson, D.N., Rothstein, M. \& Reddon, J.R. (1994). Meta-analysis of personality-job performance relations: a reply to Ones, Mount, Barrick, and Hunter (1994). Personnel Psychology, 47, 156-171.

The 15FQ+ Technical Manual. (2002). Psytech South Africa.

Van der Merwe, R.P. (2002). Psychometric testing and human resources management. fournal of Ind ustrial Psychology, 28(2), $77-86$

Vinchur, A.J., Schippmann, J.S., Switzer, E.S. \& Roth, P.L. (1998). A meta-analy tic review of predictors of job performance for salespeople. Journal of Applied Psychology, 83(4), 586-597.

Visser, D. (2002). The relation between population group and social desirability response style among South African telecommunications employees. Paper presented at the XVIth International Association for Cross-Cultural Psychology Congress, Yogyakarta, Indonesia, 15-19 July.

Visser, D. \& De Jong, A. (2001). Comparing fairness perceptions of personnel selection techniques of American, French and South African job applicants. Journal of Industrial Psychology, 27(2), 62-68

Visser, D. \& Du Toit, J.M. (2004). Using the Occupational Personality Questionnaire (OPQ) for measuring broad traits. South African Journal of Industrial Psychology, 30(4), 65-77.

Whiston, S.C. (2000). Principles and applications of assessment in counseling. Stanford: Thomson 